\title{
CONF-970834--9
}

\section{Imaging of Metallic Nano-Particles Using Plasmon/Valence Energy Loss Electrons}

\author{
E. M. Hunt*, Z. L. Wang*, N. D. Evans **, J. M. Hampikian* \\ *School of Materials Science and Engineering,Georgia Institute of Technology, Atlanta, GA 30332-0245 \\ **Oak Ridge Institute for Science and Education, P.O. Box 117, Oak Ridge, TN 37831-0117
}

Although crystal lattices can be determined reasonably well using high-resolution electron microscopy, determination of local chemistry at high spatial-resolution remains a challenge. An energy-filtering system has made it possible to perform chemically sensitive imaging in a transmission electron microscope (TEM). This type of imaging usually relies on the signal of the inner shell ionization edge, the intensity of which is affected by the threshold energy-loss and the ionization cross-section of the edge. Therefore, the spatial resolution of a core loss image image is strongly affected by the signal-tonoise ratio ${ }^{1}$. In this respect, lower loss electrons from the plasmon or valence region of the energy loss spectrum (10-100 eV) are favorable for chemically sensitive imaging due to the much higher signal intensity, provided any delocalization effects are small in comparison to the required spatial resolution. Compositionally sensitive imaging using the aluminum plasmon energy-loss electrons has been shown to produce $-2 \mathrm{~nm}$ tesolution for an atomically sharp AlTi interface. Using this resolution result the reason for the compositional contrast seen in an ion implanted specimen is postulated. The spurter deposited Al/Ti polycrystalline multilayer specimen was imaged using a JEOL 3010 TEM at $300 \mathrm{kV}$ equipped with a Gatan Imaging Filter (GIFTM). The implanted alumina sample was imaged with a GIFTM interfaced to a Philips CM30 TEM operated at $300 \mathrm{keV}$. The low-loss images were gain normalized, $512 \times 512$ pixels in size and were recorded with an exposure time of 1 second and an energy-selecting window of $5 \mathrm{eV}$.

A cross-sectional Ti/Al multilayer sample was used to determine the spatial resolution that can be expected using $15 \mathrm{eV}$ loss electrons. Figure la shows a zero loss high-resolution lattice image of an AVTi (111) interface and a loss image of the same interface recorded using Al plasmon-loss electrons. The AlTi interface is atomically sharp and is oriented parallel to the incident beam direction. To estimate the spatial resolution of the plasmon-loss electron image, a line scan is made across the Al/Ti interface, and the result is shown in Figure 1b. The fine oscillation in the intensity profile is due to the lattice fringes which arise as a result of phase contrast ${ }^{2}$. The intensity profile drops within a distance of $3 \mathrm{~nm}$ around the interface. Thus, the spatial resolution is approximately $r_{1}=1.5$ to $1.8 \mathrm{~nm}$. This spatial resolution is determined by the non-localized scattering of valence electrons ?

A single crystal alumina substrate was irxplanted at ambient temperature with $100 \mathrm{keV} \mathrm{Y} \mathrm{Y}^{+}$to a fluence of $5 \times 10^{16} \mathrm{ions} / \mathrm{cm}^{2}$. A number of techniques all indicate that the alumina surface layer was amorphized by the implantation ${ }^{3}$. Bright field TEM revealed a lack of diffraction contrast in this sample and only a diffuse electron diffraction haze associated with the presence of an amorphous phase was present. However, an optical absorption feature in the near infrared indicated the presence of nanostructures in this sample. For this reason, energy-filtered imaging was carried out. Figure 2 shows a 15 eV-loss image of this sample. This loss-image, combined with a $25 \mathrm{eV}$-loss image and an oxygen map from the same area, both of which show the particle regions as dark areas (not shown), indicate that the particles are composed primarily of metallic $\mathrm{Al}^{4}$. Using the resolution value determined above, the thickness of the Al structure in the particles shown in Figure 2 is estimated to be $\Delta d=W-r_{i} \approx 2.1 \pm 0.4 \mathrm{~nm}$. If the metallic Al is distributed in a shell, as defined by inner and outer radii, the projected atom density can be calculated across the particle for various radii as seen in Figure 3. The two calculated curves (dot-dashed lines) are normalized at $\mathrm{x}=\mathrm{r}$ for comparing the change in line scan profiles. An experimentally observed line scan intensity from a particle in Figure 2 is also plotted (dotted line). The best fit is obtained for the case with $\mathrm{r}=8 \mathrm{~nm}$ and $\mathrm{R}=11.5 \mathrm{~nm}$. Taking into consideration the broadening of the profile by the finite resolution of the plasmon energy-loss electron, a $1 \mathrm{~nm}$ width should be subtracted from the outer radius. Therefore, the thickness of the shell is $\Delta d=R-r=2.5 \mathrm{~nm}$, which is in good agreement with the estimation given above $(2.1 \pm 0.4 \mathrm{~nm})$.

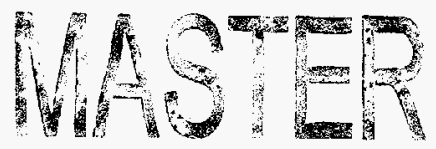

DE-AC05-96OR22464. Accordingly, the U.S. to publish of reproduce the published form of this contribution, or allow others to do so, for U.S. Government purposes." 
1. Z. L. Wang, et. al., Ultramicroscopy $60,115-135,1995$

2. Z. L. Wang, Ultramicroscopy, in press, 1997

3. E.M. Elunt, et. al., J. Mat. Sci., in press, 1996

4. E.M. Hunt, et. al., Microscopy and Microanalysis 1996, p. 534, 1996

5. Research sponsored in part by the National Science Foundation under Grant No. DMR-9624927; by the Division of Materials Sciences, U.S. Dept. of Energy, uniter contract DE-AC05-960R22464 with Lockheed Martin Energy Research Corp., through the SHaRE Program under the contract DEAC05-760R00033 with Oak Ridge Associated Universities; and by the Office of Naval Research through the Molecular Design Institute at Georgia Institute of Technology.
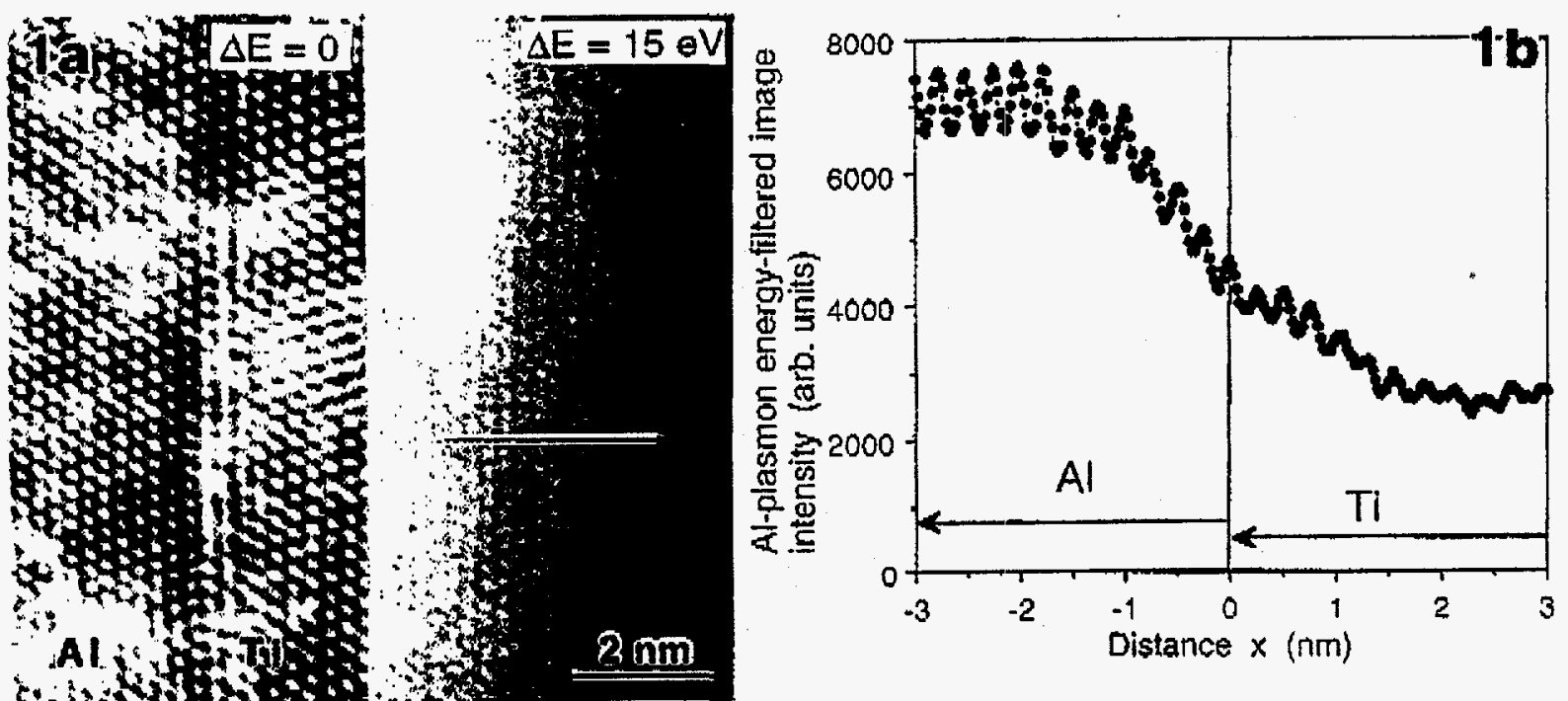

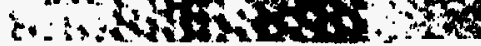
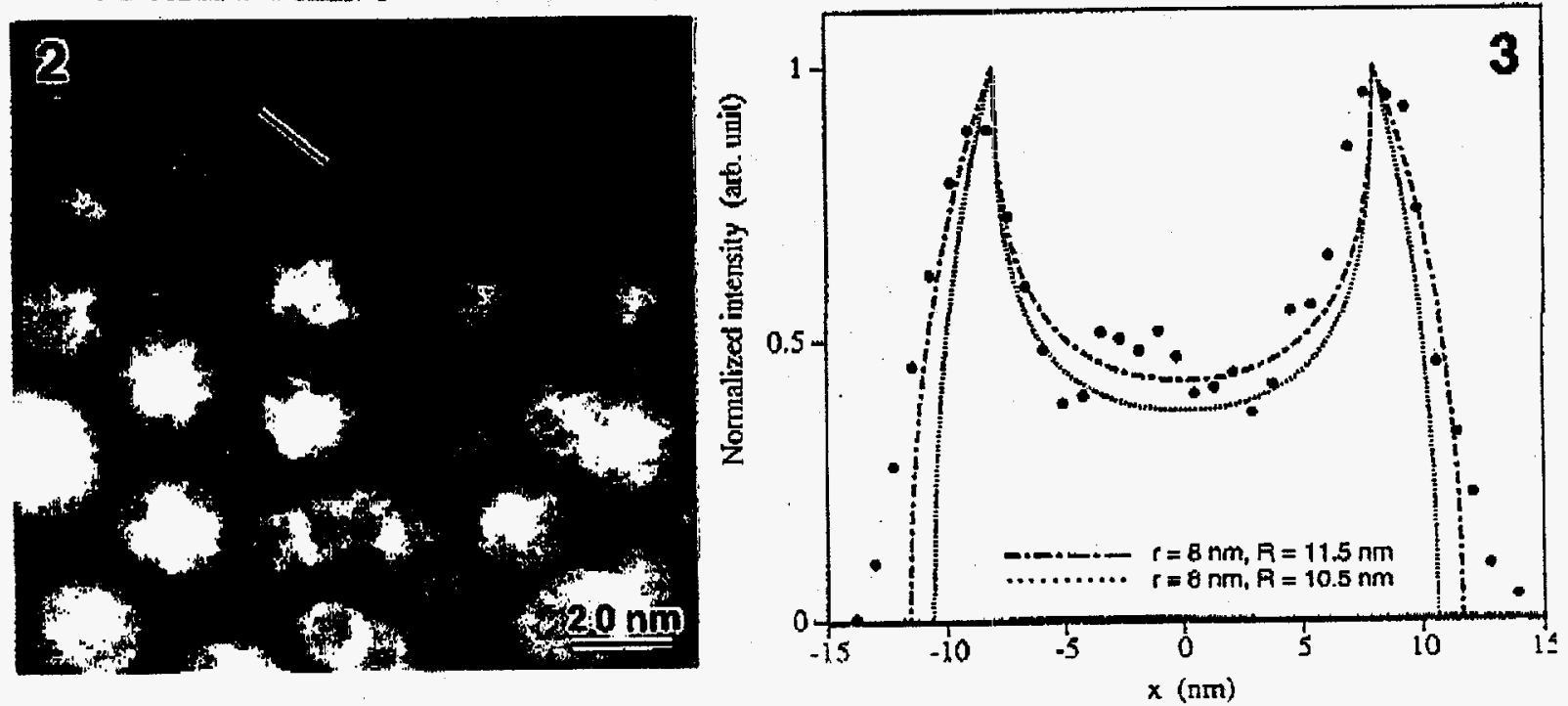


\section{DISCLAIMER}

This report was prepared as an account of work sponsored by an agency of the United States Government. Neither the United States Government nor any agency thereof, nor any of their employees, makes any warranty, express or implied, or assumes any legal liability or responsibility for the accuracy, completeness, or usefulness of any information, apparatus, product, or process disclosed, or represents that its use would not infringe privately owned rights. Reference herein to any specific commercial product, process, or service by trade name, trademark, manufacturer, or otherwise does not necessarily constitute or imply its endorsement, recommendation, or favoring by the United States Government or any agency thereof. The views and opinions of authors expressed herein do not necessarily state or reflect those of the United States Government or any agency thereof. 


\section{DISCLAMMER}

Portions of this document may be illegible in electronic image products. Images are produced from the best available original document. 